\title{
Proliferation of prenatal ultrasonography
}

\author{
John J. You MD, David A. Alter MD, Therese A. Stukel PhD, Sarah D. McDonald MD, \\ Andreas Laupacis MD, Ying Liu MSc, Joel G. Ray MD
}

Previously published at www.cmaj.ca

\section{ABSTRACT \\ Background: The extent to which temporal increases in the use of prenatal ultrasonography reflect changes in mater- nal risk is unknown. In this population-based study, we examined the use of prenatal ultrasonography from 1996 to 2006 in Ontario.}

Methods: With fiscal year $1996 / 97$ as the baseline, we evaluated the relative risk (RR) and $95 \%$ confidence interval $(\mathrm{Cl})$ for the change in rates of ultrasonography for each subsequent year. The RR was adjusted for maternal age, income, rural residence, maternal comorbidities, receipt of genetics consultation or amniocentesis - all in the index pregnancy - and history of complications in a prior pregnancy.

Results: The study sample consisted of 1399389 singleton deliveries. The rate of prenatal ultrasonography increased from 2055 per 1000 pregnancies in 1996 to 3264 per 1000 in 2006 (adjusted RR 1.55, 95\% Cl 1.54-1.55). The rate increased among both women with low-risk pregnancies (adjusted RR 1.54, 95\% Cl 1.53-1.55) and those with highrisk pregnancies (adjusted RR 1.55, 95\% Cl 1.54-1.57). The proportion of pregnancies with at least four ultrasound examinations in the second or third trimesters rose from $6.4 \%$ in 1996 to $18.7 \%$ in 2006 (adjusted RR 2.68, 95\% Cl 2.61-2.74). Paradoxically, this increase was more pronounced among low-risk pregnancies (adjusted RR 2.92, $95 \% \mathrm{Cl} 2.83-3.01$ ) than among high-risk pregnancies (adjusted RR 2.25, 95\% Cl 2.16-2.35).

Interpretation: Substantial increases in the use of prenatal ultrasonography over the past decade do not appear to reflect changes in maternal risk. Nearly one in five women now undergo four or more ultrasound examinations during the second and third trimesters. Efforts to promote more appropriate use of prenatal ultrasonography for singleton pregnancies appear warranted.

$\mathrm{T}$ he rapid proliferation of diagnostic imaging is a challenge for the containment of health care expenditures and for system sustainability in many countries. ${ }^{1}$ The ensuing debate among clinicians, researchers and policymakers has become increasingly contentious and highly politicized. ${ }^{2,3}$ In Canada, the annual operational costs for diagnostic imaging now total more than $\$ 2.2$ billion. ${ }^{4}$ Prenatal ultrasonography is one of the most rapidly proliferating imag- ing tests, this expansion being marked most strikingly by an increase in the proportion of women undergoing multiple prenatal examinations for a single pregnancy. ${ }^{5}$ Although guidelines generally recommend that two ultrasound examinations be performed in a pregnancy without complications - one in the first trimester, for measurement of nuchal translucency to screen for aneuploidy, and one in the second trimester to screen for fetal anomalies - it is conceivable that the proliferation of prenatal ultrasonography reflects changes in maternal risk over time. . $^{6-10}$

In other areas of health care, interventions that are most beneficial to high-risk individuals are frequently directed to low-risk populations. ${ }^{11-13} \mathrm{We}$ hypothesized that increasing trends in the use of prenatal ultrasonography could not be explained solely by pregnancy risk and would be evident among low-risk pregnancies. Accordingly, we performed a population-based study to examine the annual rates of prenatal ultrasonography, adjusted for maternal risk profiles.

\section{Methods}

\section{Study design}

We conducted a repeated cross-sectional population-based study of all women with a singleton obstetric delivery during the period 1996/97 to 2006/07 in Ontario, Canada's most populous province (12 million people).

\section{Data sources}

For this study, we used two linked administrative databases. We obtained records of hospital admissions from the Canadian Institute for Health Information Discharge Abstract Database. We used these records to identify obstetric deliveries and maternal comorbidities. The anonymized discharge abstracts contained a unique encrypted identifier, the patient's age, sex, date of admission, up to 16 diagnoses from the International Classification of Diseases, 9th revision, and up to 25 diagnoses from the International Classification of Diseases,

From the Departments of Medicine (You), Clinical Epidemiology and Biostatistics (You, McDonald), Obstetrics and Gynecology (McDonald) and Diag nostic Imaging (McDonald), McMaster University, Hamilton, Ont.; the Institute for Clinical Evaluative Sciences (You, Stukel, Alter, Laupacis, Liu, Ray), Toronto, Ont.; and the Keenan Research Centre (Alter, Laupacis, Ray), Li Ka Shing Knowledge Institute, St. Michael's Hospital, Toronto, Ont.

CMAJ 2010. DOI:10.1503/cmaj.090979 
10th revision. Outpatient data were obtained from the database of the Ontario Health Insurance Plan, which contains billing information for physician services, including a service date and a single diagnosis. We used the Ontario Health Insurance Plan database to identify all outpatient claims for prenatal ultrasonography. ${ }^{9}$ We also used this database to identify maternal comorbidities, because some of these conditions may be diagnosed on an outpatient basis. Neighbourhood income quintile for each patient was defined according to postal code, using census data from Statistics Canada. ${ }^{14}$

\section{Participants}

For the period Apr. 1, 1996, to Mar. 31, 2007, we identified all deliveries across all Ontario hospitals in each fiscal year. To do this, we used a main patient service code for obstetric delivery in the Discharge Abstract Database. ${ }^{15}$ Participants were women with an admission to hospital for delivery of a liveborn or stillborn singleton infant after at least 20 weeks' gestation. We excluded women younger than 15 years or older than 54 years at the date of admission to hospital for delivery and women with deliveries associated with an abortive procedure. If a woman had more than one delivery in a given fiscal year, we included only the first eligible delivery. The hospital admission date was used to define the date of the index delivery.

\section{Maternal risk profile}

We classified a pregnancy as "high-risk" if it was associated with a maternal comorbidity, genetics consultation, amniocentesis or history of complications in a prior pregnancy (see Appendix 1, available at www.cmaj.ca/cgi/content/full /cmaj.090979/DC1). We deemed all other index pregnancies to be "low-risk." We considered a maternal comorbidity to be present if any of the following diagnoses could be identified in the Ontario Health Insurance Plan database or the Discharge Abstract Database within the 12 months before (and during) the hospital stay for the index delivery: any diabetes mellitus (gestational or prepregnancy), any hypertension, thyroid disease, cardiac disease, rheumatologic disease, venous thromboembolism, renal disease or epilepsy; we also considered hospital admission for supervision of a high-risk pregnancy to represent maternal comorbidity. Similarly, we used the Ontario Health Insurance Plan database to identify claims for genetics consultation and amniocentesis during the 12 months before (and during) the hospital stay for the index delivery. Finally, we defined a history of a prior pregnancy with complications as any pregnancy in the preceding five years that had been associated with stillbirth or with a genetics consultation, amniocentesis or hospital admission for supervision of a high-risk pregnancy during the 12 months before delivery.

\section{Prenatal ultrasonography}

The main study outcome was the annual rate of utilization of prenatal ultrasonography. For each woman's index delivery in a given fiscal year, we considered all prenatal ultrasonography examinations performed during the 40 -week period before her delivery date. We ascribed each examination to the fiscal year during which she delivered. Ultrasound examinations performed on an inpatient basis are not captured by the Ontario Health Insurance Plan database.

We classified prenatal ultrasound examinations according to estimated gestational age at the time of the procedure: first trimester ( 0 to 14 weeks), second trimester (15 to 27 weeks) or third trimester (28 to 40 weeks). We estimated gestational age at the time of ultrasonography by calculating the number of days between the date of the ultrasound examination and the delivery date and assuming that the delivery occurred at 40 weeks' gestation. For example, if a woman delivered on Aug. 30, 2004, and had undergone ultrasonography on Aug. 10, 2004 (20 days before), the examination would be categorized as having taken place during the third trimester. This approach has a reported sensitivity of $90 \%$ and specificity of $99 \%{ }^{16}$

\section{Data analysis}

For each fiscal year, we computed the rate of prenatal ultrasonography by dividing the number of examinations attributed to that fiscal year by the corresponding number of inhospital singleton deliveries. We used Poisson regression to estimate the crude increase in the rate of prenatal ultrasonography within each fiscal year, relative to 1996, expressed as a relative risk (RR) and $95 \%$ confidence interval (CI). In a multivariate model, we then adjusted for maternal age, neighbourhood income quintile, rural place of residence, any diabetes mellitus (gestational or prepregnancy), any hypertension, any other maternal comorbidity (i.e., one or more of thyroid disease, cardiac disease, rheumatologic disease, venous thromboembolism, renal disease, epilepsy or admission to hospital for supervision of high-risk pregnancy), a genetics consultation and amniocentesis - all in the index pregnancy - as well as history of a prior pregnancy with complications, as defined above. We then restricted these multivariate analyses to women with a low-risk pregnancy, as well as to ultrasonography examinations performed in the second or third trimesters (to lessen the effect of a high uptake of first-trimester ultrasonography for measurement of nuchal translucency in recent years). ${ }^{17}$

In secondary analyses, we used the same multivariate model to generate the RR for undergoing prenatal ultrasonography in 2006 relative to 1996 , stratified by maternal age at delivery, neighbourhood income quintile, place of residence (urban v. rural), any maternal diabetes mellitus (yes v. no) and any maternal hypertension (yes v. no). To evaluate whether the number of ultrasound examinations performed during pregnancy changed over time, we categorized all index pregnancies in 1996 into approximate quartiles, according to the number of second- and third-trimester ultrasound examinations per pregnancy. First-trimester examinations were excluded from this particular analysis to remove the potential effect of the recent introduction of first-trimester ultrasound testing for nuchal translucency. We used the same regression models as above to estimate the adjusted RR for the proportion of women receiving the fixed categorized number of ultrasound examinations in each year relative to 1996, both for the entire cohort and stratified by low-risk versus high-risk status. 
Table 1: Characteristics of singleton pregnancies in Ontario, 1996 to 2006, $n=1399389$

Fiscal year; no. (\%) of singleton deliveries*

\begin{tabular}{|c|c|c|c|c|c|c|c|c|c|c|c|}
\hline & \\
\hline & 1996 & 1997 & 1998 & 1999 & 2000 & 2001 & 2002 & 2003 & 2004 & 2005 & 2006 \\
\hline Characteristic & 131746 & 128976 & 126841 & 126078 & 122019 & 126062 & 123502 & 127086 & 127610 & 128721 & 130748 \\
\hline $\begin{array}{l}\text { Maternal age, yr, } \\
\text { mean (SD) }\end{array}$ & $\begin{array}{l}28.9 \\
(5.4)\end{array}$ & $\begin{array}{l}29.1 \\
(5.5)\end{array}$ & $\begin{array}{l}29.1 \\
(5.5)\end{array}$ & $\begin{array}{l}29.2 \\
(5.5)\end{array}$ & $\begin{array}{l}29.3 \\
(5.6)\end{array}$ & $\begin{array}{l}29.5 \\
(5.5)\end{array}$ & $\begin{array}{l}29.6 \\
(5.5)\end{array}$ & $\begin{array}{l}29.7 \\
(5.5)\end{array}$ & $\begin{array}{l}29.7 \\
(5.5)\end{array}$ & $\begin{array}{l}29.8 \\
(5.5)\end{array}$ & $\begin{array}{l}29.8 \\
(5.5)\end{array}$ \\
\hline $15-19$ & $\begin{array}{l}6990 \\
(5.3)\end{array}$ & $\begin{array}{l}6577 \\
(5.1)\end{array}$ & $\begin{array}{l}6621 \\
(5.2)\end{array}$ & $\begin{array}{l}6010 \\
(4.8)\end{array}$ & $\begin{array}{l}5730 \\
(4.7)\end{array}$ & $\begin{array}{l}5519 \\
(4.4)\end{array}$ & $\begin{array}{l}5233 \\
(4.2)\end{array}$ & $\begin{array}{l}5148 \\
(4.1)\end{array}$ & $\begin{array}{l}4808 \\
(3.8)\end{array}$ & $\begin{array}{c}4834 \\
(3.8)\end{array}$ & $\begin{array}{l}5029 \\
(3.8)\end{array}$ \\
\hline $20-24$ & $\begin{array}{c}20683 \\
(15.7)\end{array}$ & $\begin{array}{c}20038 \\
(15.5)\end{array}$ & $\begin{array}{l}19990 \\
(15.8)\end{array}$ & $\begin{array}{l}19465 \\
(15.4)\end{array}$ & $\begin{array}{l}18762 \\
(15.4)\end{array}$ & $\begin{array}{l}18562 \\
(14.7)\end{array}$ & $\begin{array}{l}17959 \\
(14.5)\end{array}$ & $\begin{array}{l}17900 \\
(14.1)\end{array}$ & $\begin{array}{l}17861 \\
(14.0)\end{array}$ & $\begin{array}{l}17903 \\
(13.9)\end{array}$ & $\begin{array}{l}18480 \\
(14.1)\end{array}$ \\
\hline $25-29$ & $\begin{array}{l}40814 \\
(31.0)\end{array}$ & $\begin{array}{c}39576 \\
(30.7)\end{array}$ & $\begin{array}{l}38150 \\
(30.1)\end{array}$ & $\begin{array}{c}37795 \\
(30.0)\end{array}$ & $\begin{array}{c}35824 \\
(29.4)\end{array}$ & $\begin{array}{l}36829 \\
(29.2)\end{array}$ & $\begin{array}{c}35674 \\
(28.9)\end{array}$ & $\begin{array}{l}36675 \\
(28.9)\end{array}$ & $\begin{array}{c}36836 \\
(28.9)\end{array}$ & $\begin{array}{l}36796 \\
(28.6)\end{array}$ & $\begin{array}{l}36684 \\
(28.1)\end{array}$ \\
\hline $30-34$ & $\begin{array}{l}43346 \\
(32.9)\end{array}$ & $\begin{array}{l}42247 \\
(32.8)\end{array}$ & $\begin{array}{l}40707 \\
(32.1)\end{array}$ & $\begin{array}{l}40608 \\
(32.2)\end{array}$ & $\begin{array}{l}39271 \\
(32.2)\end{array}$ & $\begin{array}{c}41677 \\
(33.1)\end{array}$ & $\begin{array}{l}41188 \\
(33.4)\end{array}$ & $\begin{array}{l}42744 \\
(33.6)\end{array}$ & $\begin{array}{l}43201 \\
(33.9)\end{array}$ & $\begin{array}{l}43459 \\
(33.8)\end{array}$ & $\begin{array}{l}43874 \\
(33.6)\end{array}$ \\
\hline $35-54$ & $\begin{array}{l}19913 \\
(15.1)\end{array}$ & $\begin{array}{l}20538 \\
(15.9)\end{array}$ & $\begin{array}{l}21373 \\
(16.9)\end{array}$ & $\begin{array}{l}22200 \\
(17.6)\end{array}$ & $\begin{array}{l}22432 \\
(18.4)\end{array}$ & $\begin{array}{l}23475 \\
(18.6)\end{array}$ & $\begin{array}{c}23448 \\
(19.0)\end{array}$ & $\begin{array}{c}24619 \\
(19.4)\end{array}$ & $\begin{array}{c}24904 \\
(19.5)\end{array}$ & $\begin{array}{c}25729 \\
(20.0)\end{array}$ & $\begin{array}{c}26681 \\
(20.4)\end{array}$ \\
\hline \multicolumn{12}{|l|}{ Income quintilet } \\
\hline Q1 (lowest) & $\begin{array}{c}29414 \\
(22.3)\end{array}$ & $\begin{array}{c}28376 \\
(22.0)\end{array}$ & $\begin{array}{l}28355 \\
(22.4)\end{array}$ & $\begin{array}{c}28492 \\
(22.6)\end{array}$ & $\begin{array}{c}27558 \\
(22.6)\end{array}$ & $\begin{array}{c}27491 \\
(21.8)\end{array}$ & $\begin{array}{c}26340 \\
(21.3)\end{array}$ & $\begin{array}{c}26341 \\
(20.7)\end{array}$ & $\begin{array}{c}26078 \\
(20.4)\end{array}$ & $\begin{array}{c}25995 \\
(20.2)\end{array}$ & $\begin{array}{c}26040 \\
(19.9)\end{array}$ \\
\hline Q2 & $\begin{array}{c}27744 \\
(21.1)\end{array}$ & $\begin{array}{c}26978 \\
(20.9)\end{array}$ & $\begin{array}{c}26040 \\
(20.5)\end{array}$ & $\begin{array}{c}25659 \\
(20.4)\end{array}$ & $\begin{array}{c}24495 \\
(20.1)\end{array}$ & $\begin{array}{c}24986 \\
(19.8)\end{array}$ & $\begin{array}{c}23934 \\
(19.4)\end{array}$ & $\begin{array}{c}24477 \\
(19.3)\end{array}$ & $\begin{array}{c}23966 \\
(18.8)\end{array}$ & $\begin{array}{c}24249 \\
(18.8)\end{array}$ & $\begin{array}{c}24564 \\
(18.8)\end{array}$ \\
\hline Q3 & $\begin{array}{c}26413 \\
(20.0)\end{array}$ & $\begin{array}{c}25542 \\
(19.8)\end{array}$ & $\begin{array}{c}25262 \\
(19.9)\end{array}$ & $\begin{array}{c}24704 \\
(19.6)\end{array}$ & $\begin{array}{c}24045 \\
(19.7)\end{array}$ & $\begin{array}{c}24732 \\
(19.6)\end{array}$ & $\begin{array}{c}24083 \\
(19.5)\end{array}$ & $\begin{array}{c}24725 \\
(19.5)\end{array}$ & $\begin{array}{c}24571 \\
(19.3)\end{array}$ & $\begin{array}{c}24522 \\
(19.1)\end{array}$ & $\begin{array}{c}24935 \\
(19.1)\end{array}$ \\
\hline Q4 & $\begin{array}{c}26247 \\
(19.9)\end{array}$ & $\begin{array}{l}26191 \\
(20.3)\end{array}$ & $\begin{array}{c}25213 \\
(19.9)\end{array}$ & $\begin{array}{c}23807 \\
(18.9)\end{array}$ & $\begin{array}{c}23150 \\
(19.0)\end{array}$ & $\begin{array}{c}25045 \\
(19.9)\end{array}$ & $\begin{array}{c}25243 \\
(20.4)\end{array}$ & $\begin{array}{c}26137 \\
(20.6)\end{array}$ & $\begin{array}{c}26928 \\
(21.1)\end{array}$ & $\begin{array}{l}27208 \\
(21.1)\end{array}$ & $\begin{array}{c}27799 \\
(21.3)\end{array}$ \\
\hline Q5 (highest) & $\begin{array}{c}21133 \\
(16.0)\end{array}$ & $\begin{array}{c}21196 \\
(16.4)\end{array}$ & $\begin{array}{c}20765 \\
(16.4)\end{array}$ & $\begin{array}{c}20400 \\
(16.2)\end{array}$ & $\begin{array}{c}19841 \\
(16.3)\end{array}$ & $\begin{array}{c}20798 \\
(16.5)\end{array}$ & $\begin{array}{c}20766 \\
(16.8)\end{array}$ & $\begin{array}{c}22048 \\
(17.3)\end{array}$ & $\begin{array}{c}22498 \\
(17.6)\end{array}$ & $\begin{array}{c}23197 \\
(18.0)\end{array}$ & $\begin{array}{c}23664 \\
(18.1)\end{array}$ \\
\hline $\begin{array}{l}\text { Rural place of } \\
\text { residence }\end{array}$ & $\begin{array}{c}17565 \\
(13.3)\end{array}$ & $\begin{array}{l}16810 \\
(13.0)\end{array}$ & $\begin{array}{c}16072 \\
(12.7)\end{array}$ & $\begin{array}{c}14756 \\
(11.7)\end{array}$ & $\begin{array}{c}14094 \\
(11.6)\end{array}$ & $\begin{array}{l}14315 \\
(11.4)\end{array}$ & $\begin{array}{c}13792 \\
(11.2)\end{array}$ & $\begin{array}{l}14143 \\
(11.1)\end{array}$ & $\begin{array}{l}13929 \\
(10.9)\end{array}$ & $\begin{array}{l}13813 \\
(10.7)\end{array}$ & $\begin{array}{l}14167 \\
(10.8)\end{array}$ \\
\hline \multicolumn{12}{|l|}{ Maternal comorbidities } \\
\hline Any hypertension & $\begin{array}{l}5691 \\
(4.3)\end{array}$ & $\begin{array}{l}5994 \\
(4.6)\end{array}$ & $\begin{array}{l}5592 \\
(4.4)\end{array}$ & $\begin{array}{l}5601 \\
(4.4)\end{array}$ & $\begin{array}{l}5598 \\
(4.6)\end{array}$ & $\begin{array}{l}5486 \\
(4.4)\end{array}$ & $\begin{array}{l}5743 \\
(4.7)\end{array}$ & $\begin{array}{l}6035 \\
(4.7)\end{array}$ & $\begin{array}{l}6210 \\
(4.9)\end{array}$ & $\begin{array}{l}6305 \\
(4.9)\end{array}$ & $\begin{array}{l}6189 \\
(4.7)\end{array}$ \\
\hline Any diabetes mellitus & $\begin{array}{l}6688 \\
(5.1)\end{array}$ & $\begin{array}{l}6410 \\
(5.0)\end{array}$ & $\begin{array}{l}6331 \\
(5.0)\end{array}$ & $\begin{array}{c}6267 \\
(5.0)\end{array}$ & $\begin{array}{l}6433 \\
(5.3)\end{array}$ & $\begin{array}{c}7241 \\
(5.7)\end{array}$ & $\begin{array}{c}7495 \\
(6.1)\end{array}$ & $\begin{array}{c}7750 \\
(6.1)\end{array}$ & $\begin{array}{l}8685 \\
(6.8)\end{array}$ & $\begin{array}{l}8875 \\
(6.9)\end{array}$ & $\begin{array}{c}9596 \\
(7.3)\end{array}$ \\
\hline Other comorbidity $\ddagger$ & $\begin{array}{l}4169 \\
(3.2)\end{array}$ & $\begin{array}{l}3991 \\
(3.1)\end{array}$ & $\begin{array}{l}3998 \\
(3.2)\end{array}$ & $\begin{array}{c}4343 \\
(3.4)\end{array}$ & $\begin{array}{l}4161 \\
(3.4)\end{array}$ & $\begin{array}{c}4449 \\
(3.5)\end{array}$ & $\begin{array}{l}4038 \\
(3.3)\end{array}$ & $\begin{array}{l}4313 \\
(3.4)\end{array}$ & $\begin{array}{l}4001 \\
(3.1)\end{array}$ & $\begin{array}{c}4069 \\
(3.2)\end{array}$ & $\begin{array}{c}4202 \\
(3.2)\end{array}$ \\
\hline Genetics consultation & $\begin{array}{l}564 \\
(0.4)\end{array}$ & $\begin{array}{l}698 \\
(0.5)\end{array}$ & $\begin{array}{l}758 \\
(0.6)\end{array}$ & $\begin{array}{l}884 \\
(0.7)\end{array}$ & $\begin{array}{c}907 \\
(0.7)\end{array}$ & $\begin{array}{c}969 \\
(0.8)\end{array}$ & $\begin{array}{c}914 \\
(0.7)\end{array}$ & $\begin{array}{c}920 \\
(0.7)\end{array}$ & $\begin{array}{c}944 \\
(0.7)\end{array}$ & $\begin{array}{l}953 \\
(0.7)\end{array}$ & $\begin{array}{l}876 \\
(0.7)\end{array}$ \\
\hline Amniocentesis & $\begin{array}{l}1488 \\
(1.1)\end{array}$ & $\begin{array}{l}1682 \\
(1.3)\end{array}$ & $\begin{array}{l}1861 \\
(1.5)\end{array}$ & $\begin{array}{l}1916 \\
(1.5)\end{array}$ & $\begin{array}{l}1852 \\
(1.5)\end{array}$ & $\begin{array}{l}1868 \\
(1.5)\end{array}$ & $\begin{array}{l}1783 \\
(1.4)\end{array}$ & $\begin{array}{l}1723 \\
(1.4)\end{array}$ & $\begin{array}{l}1638 \\
(1.3)\end{array}$ & $\begin{array}{l}1592 \\
(1.2)\end{array}$ & $\begin{array}{l}1364 \\
(1.0)\end{array}$ \\
\hline \multicolumn{12}{|l|}{ Pregnancy in prior 5 yr } \\
\hline None & $\begin{array}{c}75279 \\
(57.1)\end{array}$ & $\begin{array}{l}74231 \\
(57.6)\end{array}$ & $\begin{array}{l}73421 \\
(57.9)\end{array}$ & $\begin{array}{c}74089 \\
(58.8)\end{array}$ & $\begin{array}{c}72919 \\
(59.8)\end{array}$ & $\begin{array}{c}75287 \\
(59.7)\end{array}$ & $\begin{array}{c}75137 \\
(60.8)\end{array}$ & $\begin{array}{c}77816 \\
(61.2)\end{array}$ & $\begin{array}{c}78231 \\
(61.3)\end{array}$ & $\begin{array}{c}77758 \\
(60.4)\end{array}$ & $\begin{array}{l}79133 \\
(60.5)\end{array}$ \\
\hline Without complications & $\begin{array}{c}53466 \\
(40.6)\end{array}$ & $\begin{array}{c}51459 \\
(39.9)\end{array}$ & $\begin{array}{c}49792 \\
(39.3)\end{array}$ & $\begin{array}{c}48139 \\
(38.2)\end{array}$ & $\begin{array}{c}45071 \\
(36.9)\end{array}$ & $\begin{array}{c}46584 \\
(37.0)\end{array}$ & $\begin{array}{c}44379 \\
(35.9)\end{array}$ & $\begin{array}{c}45273 \\
(35.6)\end{array}$ & $\begin{array}{c}45338 \\
(35.5)\end{array}$ & $\begin{array}{c}46784 \\
(36.3)\end{array}$ & $\begin{array}{c}47556 \\
(36.4)\end{array}$ \\
\hline With complications§ & $\begin{array}{c}3001 \\
(2.3)\end{array}$ & $\begin{array}{l}3286 \\
(2.5)\end{array}$ & $\begin{array}{c}3628 \\
(2.9)\end{array}$ & $\begin{array}{c}3850 \\
(3.1)\end{array}$ & $\begin{array}{l}4029 \\
(3.3)\end{array}$ & $\begin{array}{l}4191 \\
(3.3)\end{array}$ & $\begin{array}{l}3986 \\
(3.2)\end{array}$ & $\begin{array}{c}3997 \\
(3.1)\end{array}$ & $\begin{array}{l}4041 \\
(3.2)\end{array}$ & $\begin{array}{l}4179 \\
(3.2)\end{array}$ & $\begin{array}{c}4059 \\
(3.1)\end{array}$ \\
\hline High-risk pregnancyๆl & $\begin{array}{c}20634 \\
(15.7)\end{array}$ & $\begin{array}{c}20629 \\
(16.0)\end{array}$ & $\begin{array}{c}20596 \\
(16.2)\end{array}$ & $\begin{array}{c}21002 \\
(16.7)\end{array}$ & $\begin{array}{c}21050 \\
(17.3)\end{array}$ & $\begin{array}{l}22160 \\
(17.6)\end{array}$ & $\begin{array}{c}22060 \\
(17.9)\end{array}$ & $\begin{array}{c}22958 \\
(18.1)\end{array}$ & $\begin{array}{c}23888 \\
(18.7)\end{array}$ & $\begin{array}{c}24385 \\
(18.9)\end{array}$ & $\begin{array}{c}25178 \\
(19.3)\end{array}$ \\
\hline
\end{tabular}

Note: $\mathrm{Q}=$ quintile, $\mathrm{SD}=$ standard deviation.

*Unless indicated otherwise.

tIncome quintiles for each fiscal year do not sum to $100 \%$ because of missing data for up to $3 \%$ of patients.

‡Thyroid disease, cardiac disease, rheumatologic disease, venous thromboembolism, renal disease, epilepsy or admission to hospital for supervision of high-risk pregnancy.

$\S$ Defined as prior pregnancy associated with genetics consultation, amniocentesis, admission to hospital for supervision of high-risk pregnancy or pregnancy ending in stillbirth.

१Defined as any hypertension, any diabetes mellitus, any other comorbidity (as defined above), genetics consultation or amniocentesis during index pregnancy or history of pregnancy with complications (as defined above). 
The study was approved by the Sunnybrook Health Sciences Centre Research Ethics Board.

\section{Results}

We captured data for 1424767 in-hospital deliveries over the 11 -year study period. A total of 25378 deliveries were excluded because of multiple-gestation pregnancies $(n=$ 22 785), a second delivery within the same fiscal year $(n=$ $1628)$, extremes of maternal age $(n=665)$ or delivery after 20 weeks' gestation in association with an abortive procedure $(n=300)$. The final study sample was 1399389 singleton deliveries (Table 1).

The annual number of ultrasound examinations increased linearly over the study period ( $p$ for trend $<0.001$; Figure 1 ). The rate rose from 2055 per 1000 pregnancies in 1996 to 3264 per 1000 in 2006, which represents a crude 11-year RR (i.e., increase in utilization) of 1.59 (95\% CI 1.58-1.60) and an adjusted RR of 1.55 (95\% CI 1.54-1.55) (Table 2).

The magnitude of the increase in ultrasonography rates over the 11-year study period was similar for women with low-risk pregnancies (adjusted RR 1.54, 95\% CI 1.53-1.55, 2006 relative to 1996) and those with high-risk pregnancies (adjusted RR 1.55, 95\% CI 1.54-1.57) (Figure 1, Table 2) and for examinations performed in the second and third trimesters (adjusted RR 1.45, 95\% CI 1.44-1.46) (Figure 1). Although within-stratum interactions were statistically significant $(p<0.001)$, the magnitude of the adjusted RRs was comparable upon stratification by maternal characteristics (Figure 2). The relative increase in ultrasonography across the 11-year study period was evident in all trimesters, but was most pronounced for examinations performed in the first trimester (Figure 2).

In 1996, the quartiles for the number of ultrasound examinations performed in the second and third trimesters were zero or one, two, three, and four or more (Table 3). Among all women, the proportion of pregnancies with four or more fetal ultrasound examinations in the second or third trimester rose from $6.4 \%$ in 1996 to $18.7 \%$ in 2006 , corresponding to an adjusted RR of 2.68 (95\% CI 2.61-2.74) across the decade. This change was more pronounced among low-risk pregnancies (adjusted RR, 2.92, 95\% CI 2.83-3.01) than among high-risk pregnancies (adjusted RR 2.25, 95\% CI 2.16-2.35). By 2006, more than one-third (37.2\%) of all women were receiving three or more ultrasound examinations during the second and third trimesters of pregnancy (Table 3).

\section{Interpretation}

In a health care system with universal access to prenatal services, we observed a 55\% relative increase (adjusted) in the use of outpatient obstetric ultrasonography among singleton pregnancies over the decade from 1996/97 to 2006/07. This change was statistically significant and robust across subgroups, regardless of pregnancy risk, maternal demographic characteristics or maternal comorbidities. By 2006, over onethird of women with a singleton pregnancy were undergoing three or more outpatient ultrasound examinations during the second and third trimesters.
Our findings are consistent with a growing body of evidence suggesting that some health interventions most beneficial to high-risk individuals are frequently directed at apparently low-risk populations. This "treatment-risk paradox" has been described for statin therapy in high-risk elderly patients, ${ }^{11}$ for pharmacotherapy in patients with congestive heart failure ${ }^{12}$ and for temporal trends in the utilization of noninvasive cardiac testing. ${ }^{13}$ Although the use of prenatal ultrasonography among women with low-risk pregnancies may not account for a large proportion of total expenditures for medical imaging, it serves as a test case of a rapidly proliferating diagnostic technology. As such, it is a microcosm of a much bigger phenomenon that may be occurring with many other diagnostic imaging tests and that, cumulatively, may account for billions of dollars of health care expenditures. ${ }^{1,2}$

Others have documented substantial regional differences in utilization of obstetric ultrasonography and evidence of inappropriate use of this technology. ${ }^{5,18-20}$ In our study, rising utilization could not be explained solely by increases in maternal age, changes in maternal risk profiles or increases in uptake of first-trimester scanning for nuchal translucency. Hence, it would appear that nonclinical factors may largely explain the increases in prenatal ultrasonography that we observed. These factors may include the practice of defensive medicine, the desire to reassure a patient that her pregnancy is progressing normally, patient demand and even the "entertainment" value of seeing one's fetus. ${ }^{21-24}$ Although the benefits of prenatal ultrasonography in high-risk pregnancies may be clearer, the value of repeat ultrasonography in low-risk patients is not. ${ }^{25,26}$ Prenatal ultrasonography is widely regarded as safe. ${ }^{27}$ However, some studies have suggested that frequent prenatal ultrasonography may be associated with intrauterine growth restriction, delayed speech and non-righthandedness. ${ }^{28-31}$ Moreover, when a prenatal ultrasound examination is performed in a low-risk pregnancy, unintended harmful consequences may outweigh any potential benefits. For example, incidental benign findings - which are becoming increasingly prevalent with advances in technology can cause anxiety and can lead to additional investigations, some of which may be invasive, such as amniocentesis. ${ }^{32}$

More than one-third of women now undergo three or more ultrasound examinations during the second and third trimesters of a singleton pregnancy, a rate that appears to be climbing for reasons unrelated to changes in maternal risk. As such, there is a need for patients, clinicians and policy-makers to carefully consider the optimal number of obstetric ultrasound examinations per pregnancy. Assuming an average cost of \$64 per examination (based on the 2008 fee schedule in Ontario ${ }^{33}$ ), we estimate that the cumulative amount in fees for additional prenatal ultrasound examinations performed since 1996 was \$30 million. Given the high aggregate costs of prenatal ultrasonography (because pregnancy is so common) and the evidence of potential overuse in populations not at high risk, health policy-makers could make a legitimate argument that costs be contained in groups for whom there is no documented benefit. Indeed, after the first trimester, most current guidelines recommend only a single second-trimester anatomic ultrasound examination during a pregnancy without 
complications. ${ }^{6,7}$ However, obstetricians function in the highest-risk medico-legal environment, where the implicit rules governing practice may differ from those in other domains of medicine, including the need to reassure patients through safe and relatively inexpensive tests like ultrasonography. ${ }^{21,22}$ In publicly funded health systems, citizens are key stakeholders in this debate, and efforts to engage citizens in deliberations about setting health care priorities should be encouraged. ${ }^{34}$ Various options for optimizing the use of obstetric ultrasonography, such as preauthorization of claims and changes to the fee schedule, will require debate and will necessarily demand a balance between policy pragmatism and an honest

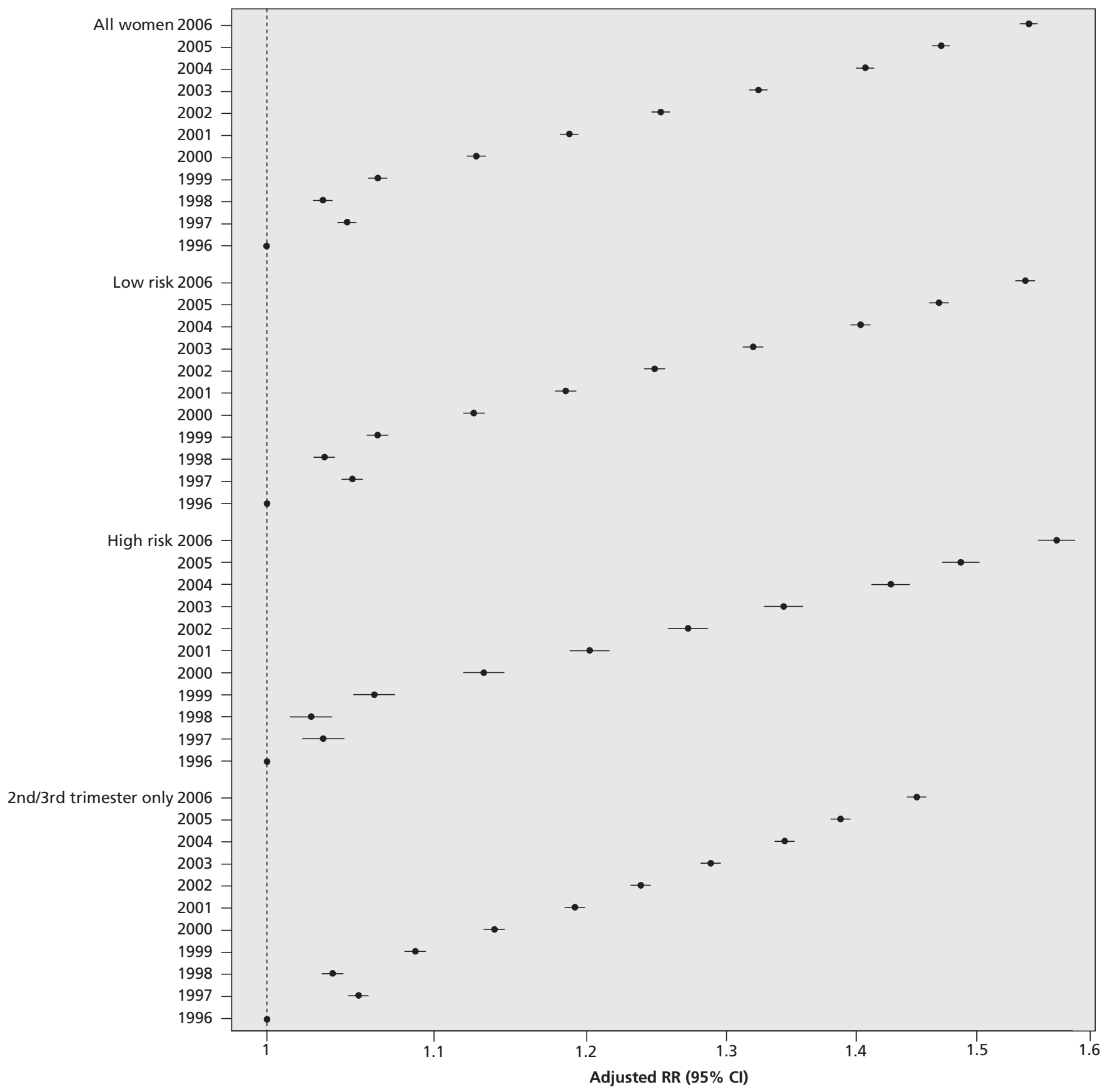

Figure 1: Relative risk (RR) of undergoing obstetric ultrasonography from fiscal year 1996/97 to fiscal year 2006/07. Increases in the annual rate of prenatal ultrasonography are expressed as relative risk, with fiscal year 1996/97 as the referent. Data were adjusted for maternal age, income quintile, rural versus urban place of residence, any diabetes mellitus, any hypertension, any other maternal comorbidity, genetics consultation and amniocentesis - all in the index pregnancy - and a history of complications in a prior pregnancy. For all trends, $p<0.001 . \mathrm{Cl}=$ confidence interval. 


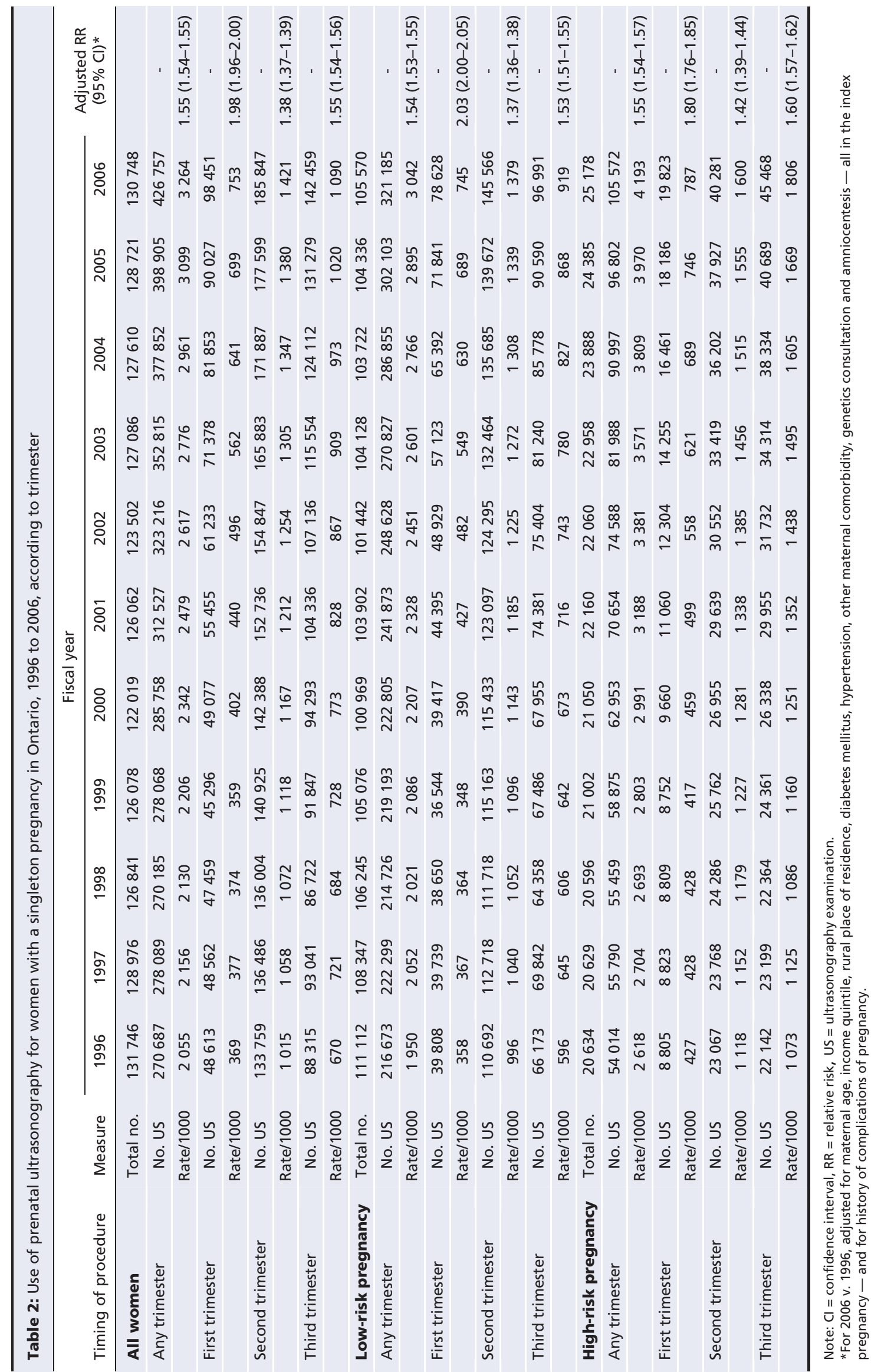


acknowledgement of defensive practice styles among individual providers.

Our study has some limitations. First, we had to estimate the trimester in which ultrasonography had been performed. Therefore, for preterm deliveries, some examinations actually completed in the first or second trimester would have been ascribed to a later period in the pregnancy, which would have led us to underestimate the number of first-trimester examinations. To counter this effect, we excluded multifetal pregnancies and adjusted for maternal risk, each of which is more likely to result in preterm delivery. Second, we excluded women who aborted before 20 weeks' gestation, some of whom might have been considered to be at high risk. The remaining women in our study cohort whose pregnancies

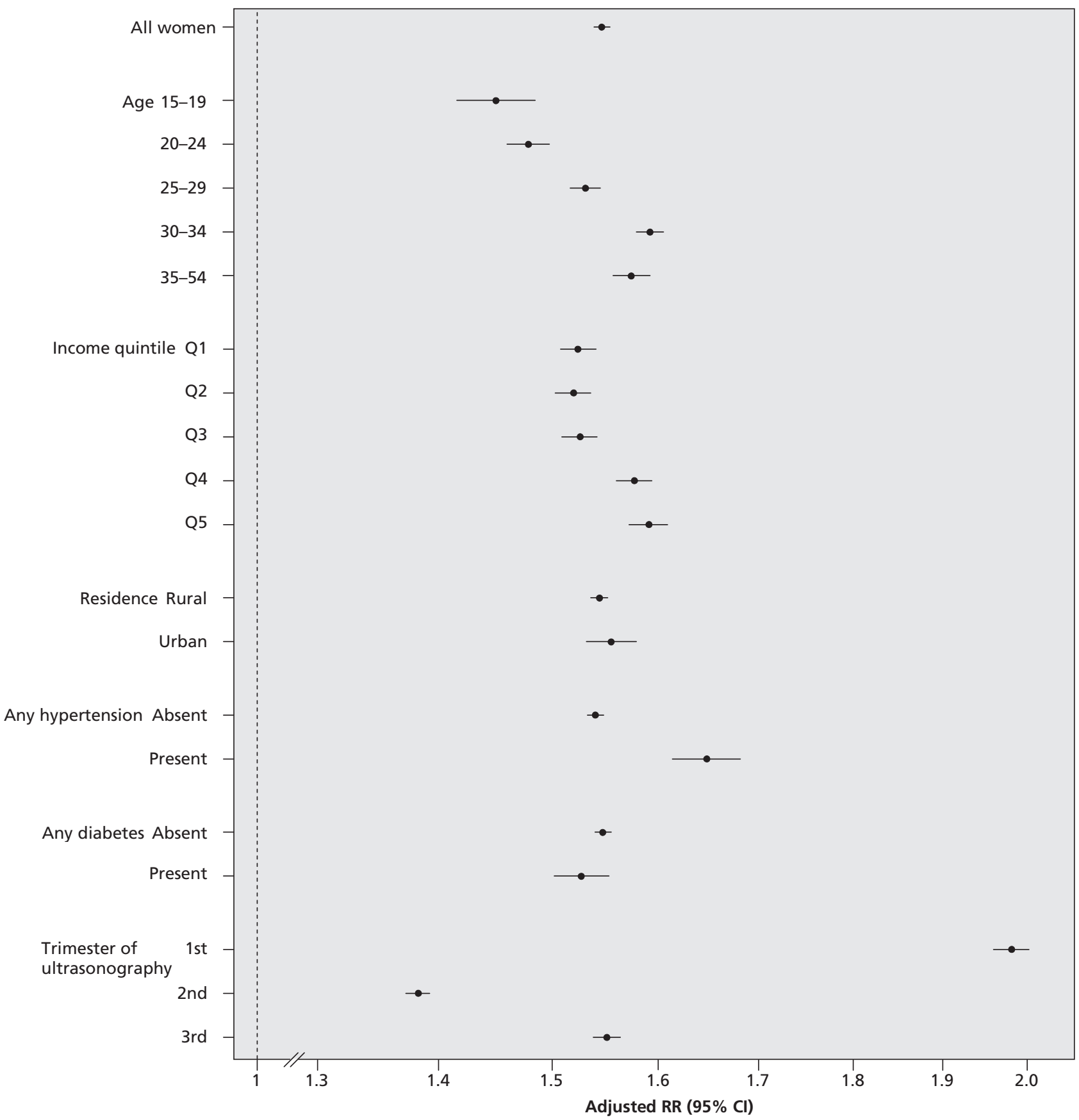

Figure 2: Relative risk (RR) of undergoing obstetric ultrasonography in fiscal year 2006/07 relative to fiscal year 1996/97. Data were adjusted for maternal age, income quintile, rural versus urban place of residence, any diabetes mellitus, any hypertension, any other maternal comorbidity, genetics consultation and amniocentesis - all in the index pregnancy - and a history of complications in a prior pregnancy. For all within-stratum interaction terms, $p<0.001 . \mathrm{Cl}=$ confidence interval. 


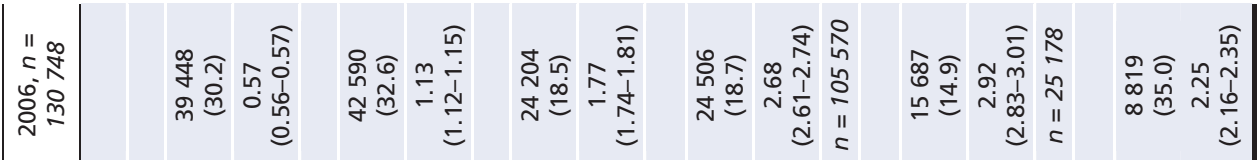

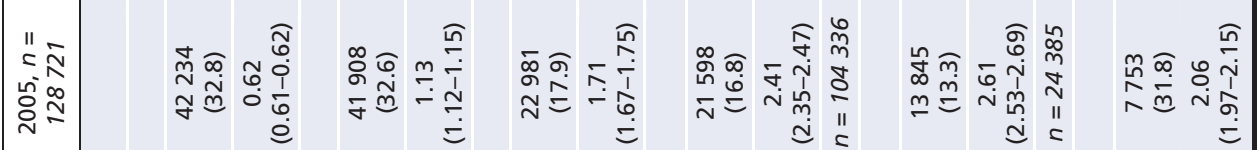

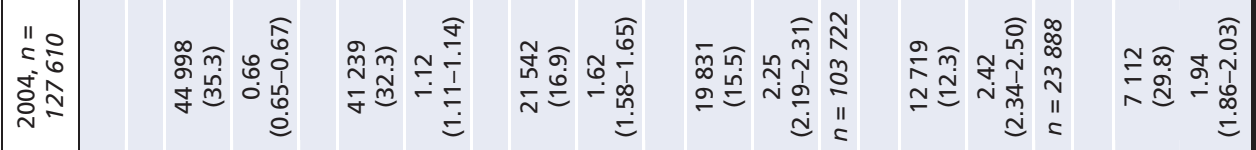

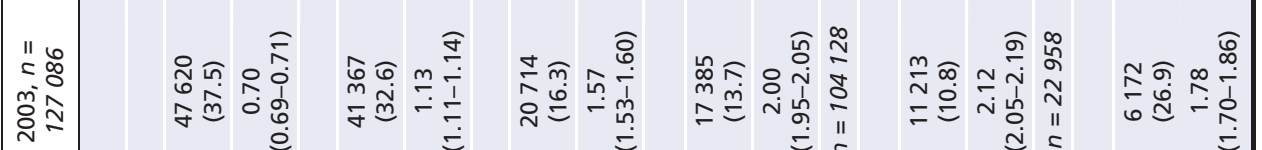

资

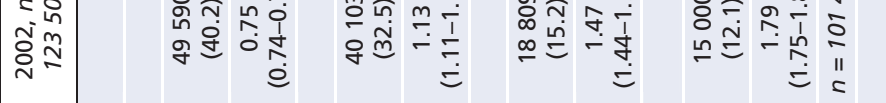

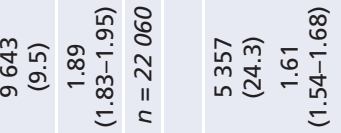

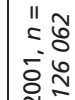

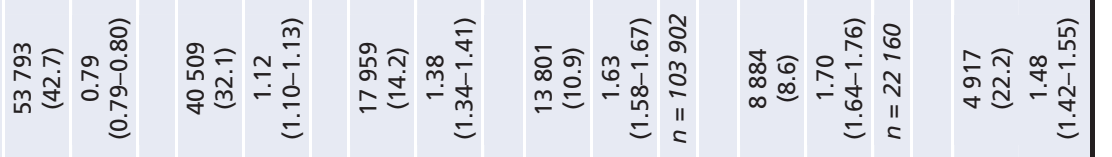

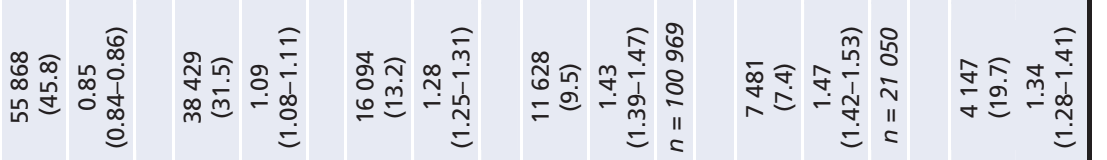

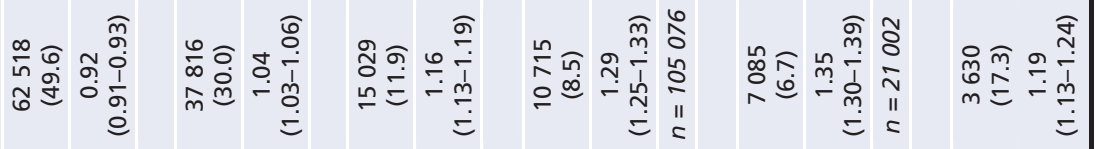

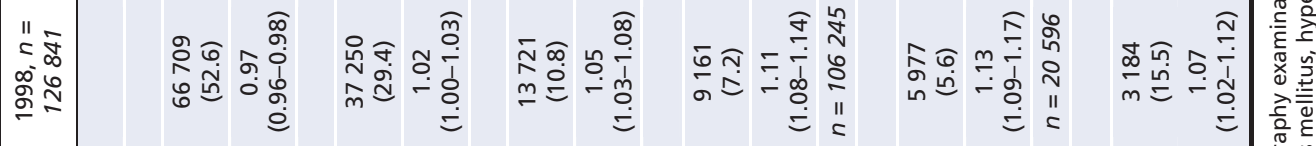

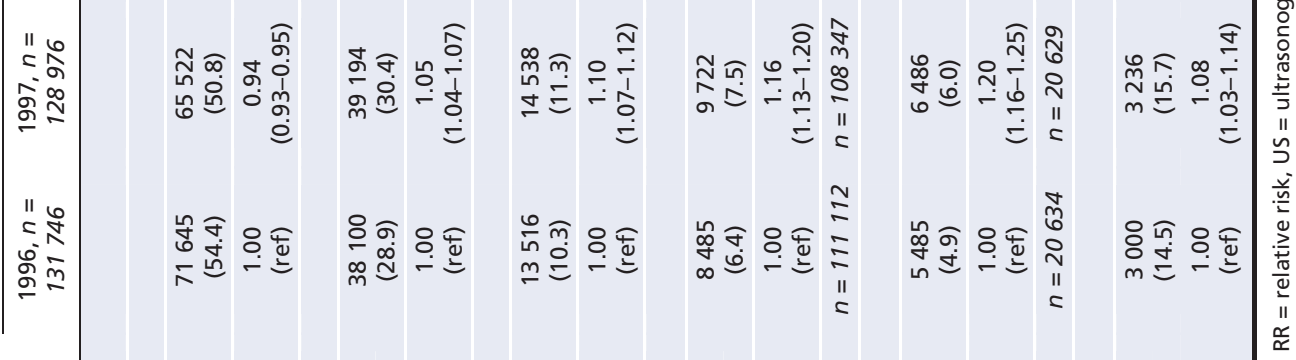

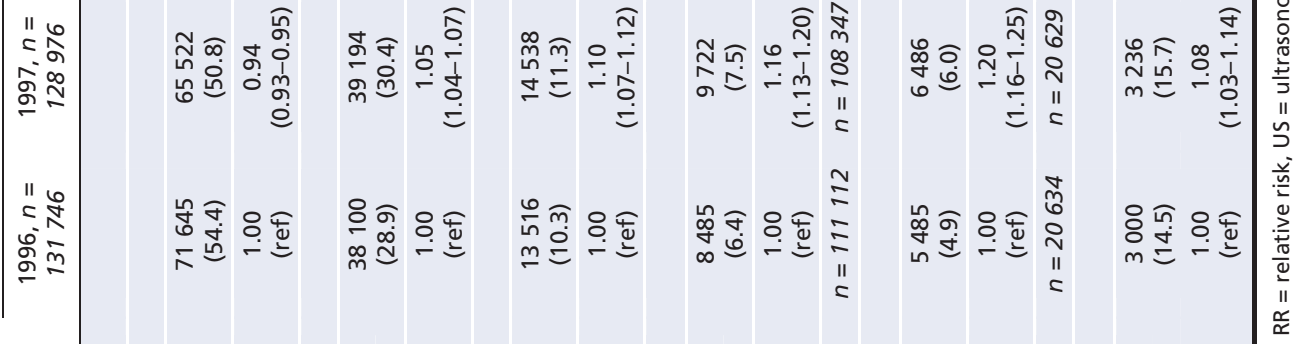

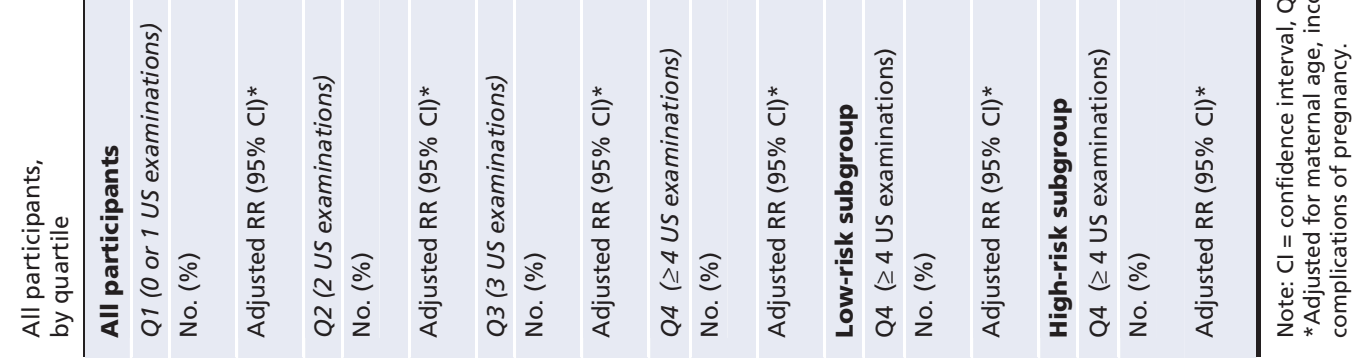


were defined as "high-risk" might have had a lower disease burden than the entire population of women with high-risk pregnancies, which might have limited somewhat the generalizability of our findings to pregnancies extending beyond 20 weeks' gestation. Third, we did not have data about trends in the locations where the prenatal ultrasound examinations were performed, such as private physicians' offices versus hospital-based facilities. Future studies will be needed to examine potential system-level reasons for the trends we observed. Finally, since the Ontario Health Insurance Plan database does not provide the indications for prenatal ultrasonography, we could not directly assess the appropriateness of the patterns of use that we observed. A detailed chart review, combined with surveys or interviews of mothers and their pregnancy caregivers, might better elucidate the underlying reasons for the rising use of prenatal ultrasonography.

In conclusion, there has been a substantial increase in the use of prenatal ultrasonography in the past decade, and more than one-third of women with a singleton pregnancy now receive three or more ultrasound examinations during the second and third trimesters. Efforts to promote more appropriate use of prenatal ultrasonography in low-risk groups appear warranted, but careful debate will be required to determine the most effective and acceptable approaches to achieve this goal.

This article has been peer reviewed.

Competing interests: None declared.

Contributors: All authors contributed to the concept and design of the study. Drs. You and Ray drafted the manuscript. All authors contributed to the analysis and interpretation of data, critically revised the manuscript for important intellectual content and approved the final version.

Funding: John You is supported by a Career Scientist Award from the Ontario Ministry of Health and Long-Term Care. Joel Ray is supported by a New Investigator Award from the Canadian Institutes of Health Research. The Institute for Clinical Evaluative Sciences receives core operating funding in the form of an annual grant from the Ontario Ministry of Health and LongTerm Care. This study was funded by an operating grant from the Canadian Institutes of Health Research and was supported by the Institute for Clinical Evaluative Sciences. None of the funding sources had a role in the design and conduct of the study; the collection, management, analysis or interpretation of the data; or the preparation, review or approval of the manuscript. The opinions, results and conclusions reported in this paper are those of the authors and are independent from the funding sources. No endorsement by the Institute for Clinical Evaluative Sciences or the Ontario Ministry of Health and Long-Term Care is intended or should be inferred.

\section{REFERENCES}

1. Iglehart JK. The new era of medical imaging — progress and pitfalls. $N$ Engl $J$ Med 2006;354:2822-8.

2. Iglehart JK. Health insurers and medical-imaging policy - a work in progress. $N$ Engl J Med 2009;360:1030-7.

3. Redberg RF, Walsh J. Pay now, benefits may follow - the case of cardiac computed tomographic angiography. N Engl J Med 2008;359:2309-11.

4. Canadian Institute for Health Information. Medical imaging in Canada, 2007. Ottawa (ON): The Institute; 2008. Available: http://secure.cihi.ca/cihiweb/dispPage .jsp?cw_page=PG_877_E\&cw_topic=877\&cw_rel=AR_1043_E\#full (accessed 2009 Nov. 5).
5. You JJ, Alter DA, Iron K, et al. Diagnostic services in Ontario: descriptive analysis and jurisdictional review. Toronto $(\mathrm{ON})$ : Institute for Clinical Evaluative Sciences; 2007.

6. Periodic health examination, 1992 update: 2 . Routine prenatal ultrasound screening Canadian Task Force on the Periodic Health Examination. CMAJ 1992;147:627-33.

7. US Preventive Services Task Force. Screening ultrasonography in pregnancy. In: Guide to clinical preventive services: report of the U.S. Preventive Services Task Force. 2nd ed. Baltimore (MD): Williams and Wilkins; 1996. p. 407-17. Available: www.ncbi.nlm.nih.gov/bookshelf/br.fcgi?book=hscps2ed1996\&part= A14038 (accessed 2009 Nov. 5).

8. Summers AM, Langlois S, Wyatt P, et al. Prenatal screening for fetal aneuploidy. $J$ Obstet Gynaecol Can 2007;29:146-79.

9. Huang L, Sauve R, Birkett N, et al. Maternal age and risk of stillbirth: a systematic review. CMAJ 2008;178:165-72.

10. Heffner LJ. Advanced maternal age. How old is too old? N Engl J Med 2004;351: 1927-9.

11. Ko DT, Mamdani M, Alter DA. Lipid-lowering therapy with statins in high-risk elderly patients: the treatment-risk paradox. JAMA 2004;291:1864-70.

12. Lee DS, Tu JV, Juurlink DN, et al. Risk-treatment mismatch in the pharmacotherapy of heart failure. JAMA 2005;294:1240-7.

13. Alter DA, Stukel TA, Newman A. Proliferation of cardiac technology in Canada: a challenge to the sustainability of Medicare. Circulation 2006;113:380-7.

14. Wilkins R. PCCF+version 4J user's guide: automated geographic coding based on the Statistics Canada postal code conversion files, including postal codes through September 2006. Ottawa (ON): Statistics Canada; 2007.

15. Ray JG, Vermeulen MJ, Schull MJ, et al. Cardiovascular health after maternal placental syndromes (CHAMPS): population-based retrospective cohort study. Lancet 2005;366:1797-803.

16. Toh S, Mitchell AA, Werler MM, et al. Sensitivity and specificity of computerized algorithms to classify gestational periods in the absence of information on date of conception. Am J Epidemiol 2008;167:633-40.

17. Ndumbe FM, Navti O, Chilaka VN, et al. Prenatal diagnosis in the first trimester of pregnancy. Obstet Gynecol Surv 2008;63:317-28.

18. Thompson E, Freake D, Worrall G. Are rural general practitioner-obstetricians performing too many prenatal ultrasound examinations? Evidence from western Labrador. CMAJ 1998;158:307-13.

19. Jorgensen FS. An epidemiological study of obstetric ultrasound examinations in Denmark 1989-1990. Acta Obstet Gynecol Scand 1992;71:513-9.

20. Yates JM, Lumley J, Bell RJ. The prevalence and timing of obstetric ultrasound in Victoria 1991-1992: a population-based study. Aust N Z J Obstet Gynaecol 1995;35:375-9.

21. Studdert DM, Mello MM, Sage WM, et al. Defensive medicine among high-risk specialist physicians in a volatile malpractice environment. JAMA 2005;293:2609-17.

22. Meire HB. Ultrasound-related litigation in obstetrics and gynecology: the need for defensive scanning. Ultrasound Obstet Gynecol 1996;7:233-5.

23. Gudex C, Nielsen BL, Madsen M. Why women want prenatal ultrasound in normal pregnancy. Ultrasound Obstet Gynecol 2006;27:145-50.

24. Simonsen SE, Branch DW, Rose NC. The complexity of fetal imaging: reconciling clinical care with patient entertainment. Obstet Gynecol 2008;112:1351-4.

25. Neilson JP, Alfirevic Z. Doppler ultrasound for fetal assessment in high risk pregnancies [review]. Cochrane Database Syst Rev 2000;(2):CD000073.

26. Bricker L, Neilson JP, Dowswell T. Routine ultrasound in late pregnancy (after 24 weeks' gestation) [review]. Cochrane Database Syst Rev 2008;(4):CD001451.

27. Consensus conference: the use of diagnostic ultrasound imaging during pregnancy. JAMA 1984;252:669-72.

28. Newnham JP, Evans SF, Michael CA, et al. Effects of frequent ultrasound during pregnancy: a randomised controlled trial. Lancet 1993;342:887-91.

29. Campbell JD, Elford RW, Brant RF. Case-control study of prenatal ultrasonography exposure in children with delayed speech. CMAJ 1993;149:1435-40.

30. Kieler H, Axelsson O, Haglund B, et al. Routine ultrasound screening in pregnancy and the children's subsequent handedness. Early Hum Dev 1998;50:233-45.

31. Salvesen KA, Vatten LJ, Eik-Nes SH, et al. Routine ultrasonography in utero and subsequent handedness and neurological development. BMJ 1993;307:159-64.

32. Bethune $M$. Time to reconsider our approach to echogenic intracardiac focus and choroid plexus cysts. Aust N Z J Obstet Gynaecol 2008;48:137-41.

33. Diagnostic radiology. In: Ontario Health Insurance Plan (OHIP) schedule of benefits and fees. Toronto $(\mathrm{ON})$ : Ontario Ministry of Health and Long-Term Care; 2009. Available: www.health.gov.on.ca/english/providers/program/ohip/sob /physserv/d_radiol.pdf (accessed 2009 May 1).

34. Bruni RA, Laupacis A, Martin DK. Public engagement in setting priorities in health care. CMAJ 2008;179:15-8.

Correspondence to: Dr. John J. You, Department of Medicine, McMaster University, 1200 Main St. W, HSC-3V51, Hamilton ON L8N3Z5; jyou@mcmaster.ca 